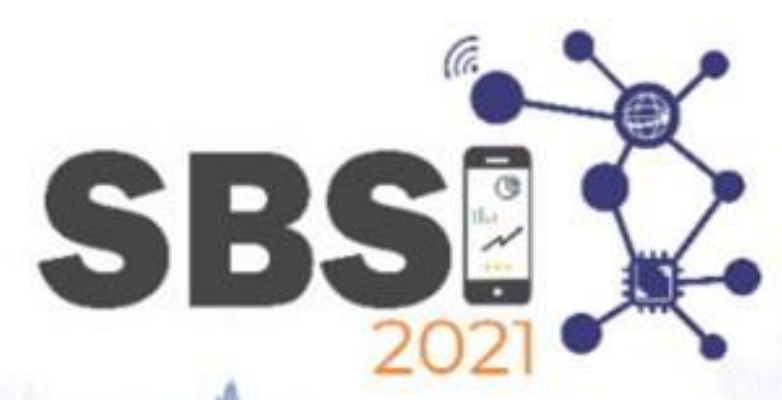

\title{
PROMOTING DIGITAL ENTREPRENEURSHIP TO MITIGATE THE IMPACTS CAUSED BY THE COVID- 19 PANDEMIC
}

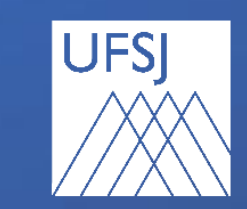
Universidade Federa
Alice Ferreira Cunha (alice_cunha10@hotmail.com) Fábio Corrêa (fabiocontact@gmail.com)

Universidade Federal de São João del-Rei

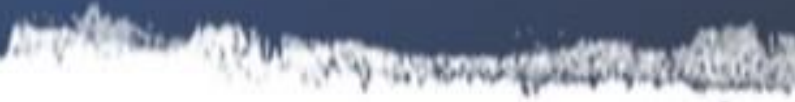

1

\section{UUFU}

Faculdade de Computaçẩo

Organização

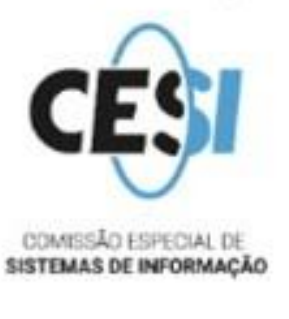

$\widehat{\text { acm }}$ In-Cooperation
Dárlinton Barbosa Feres Carvalho (darlinton@acm.org) Fabrício Molica de Mendonça (fabriciomolica@ufsj.edu.br)

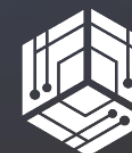

5 I

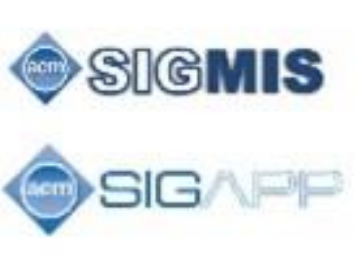

CSIGNVF

Apoio/Cooperação 


\section{INTRODUÇÃO}

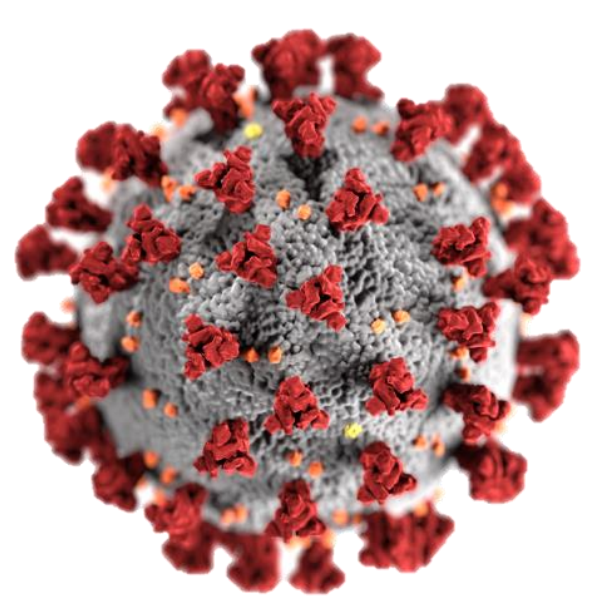

COVID-19

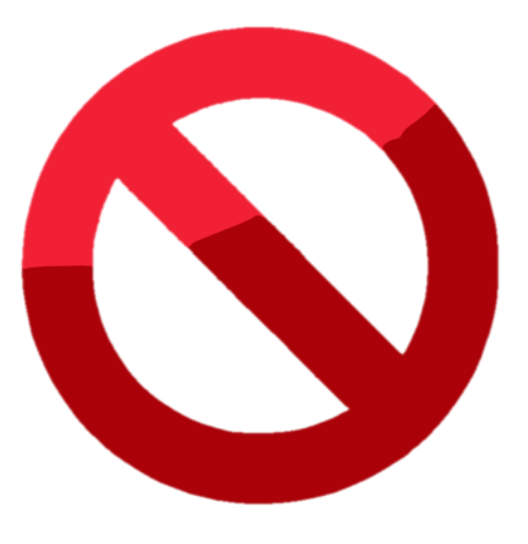

RESTRIÇÕES

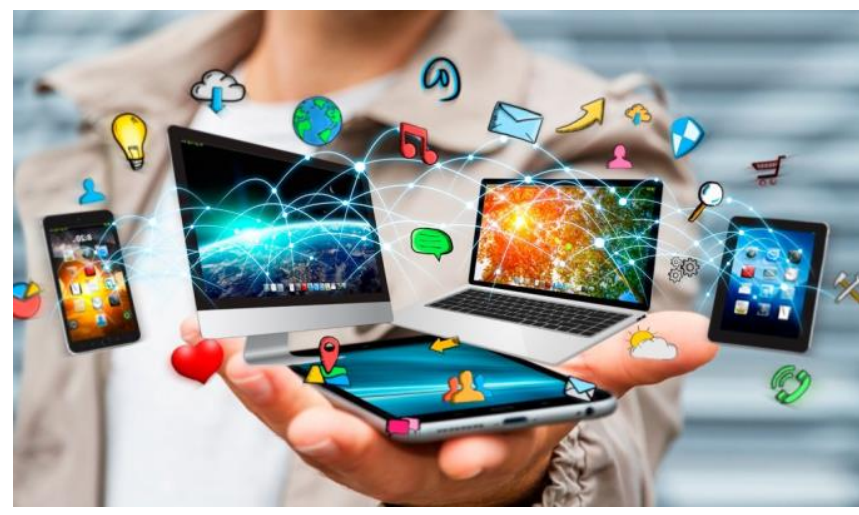

DIGITALIZAÇÃo 


\section{INTRODUÇÃO}

- Habilidades técnicas

- Habilidades comportamentais

- Mentalidade empreendedora
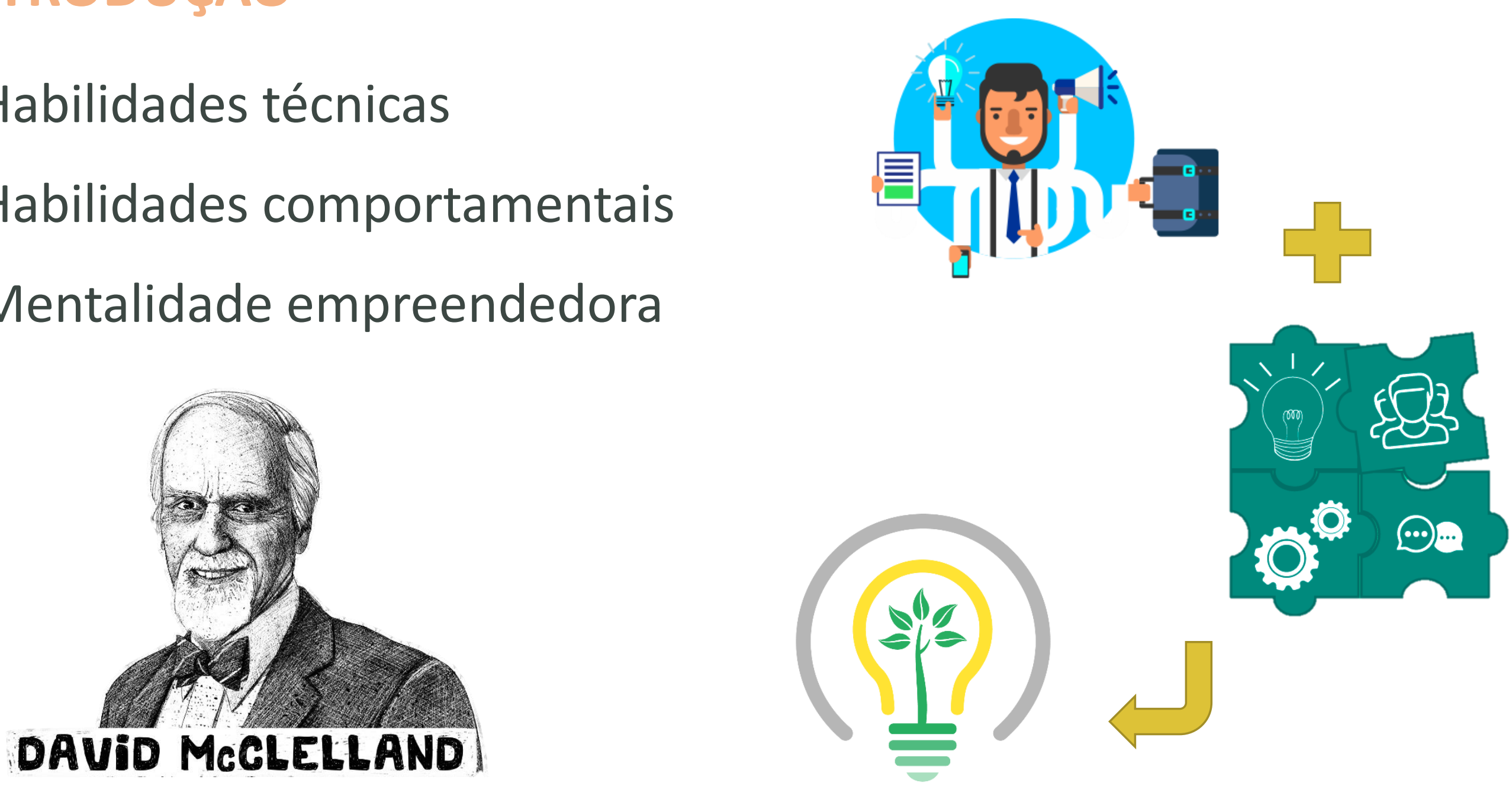


\section{INTRODUÇÃO}

- Desenvolvimento de sistemas computacionais

- Iniciativas orientadas a educação básica em informática

- Desenvolvimento do pensamento computacional

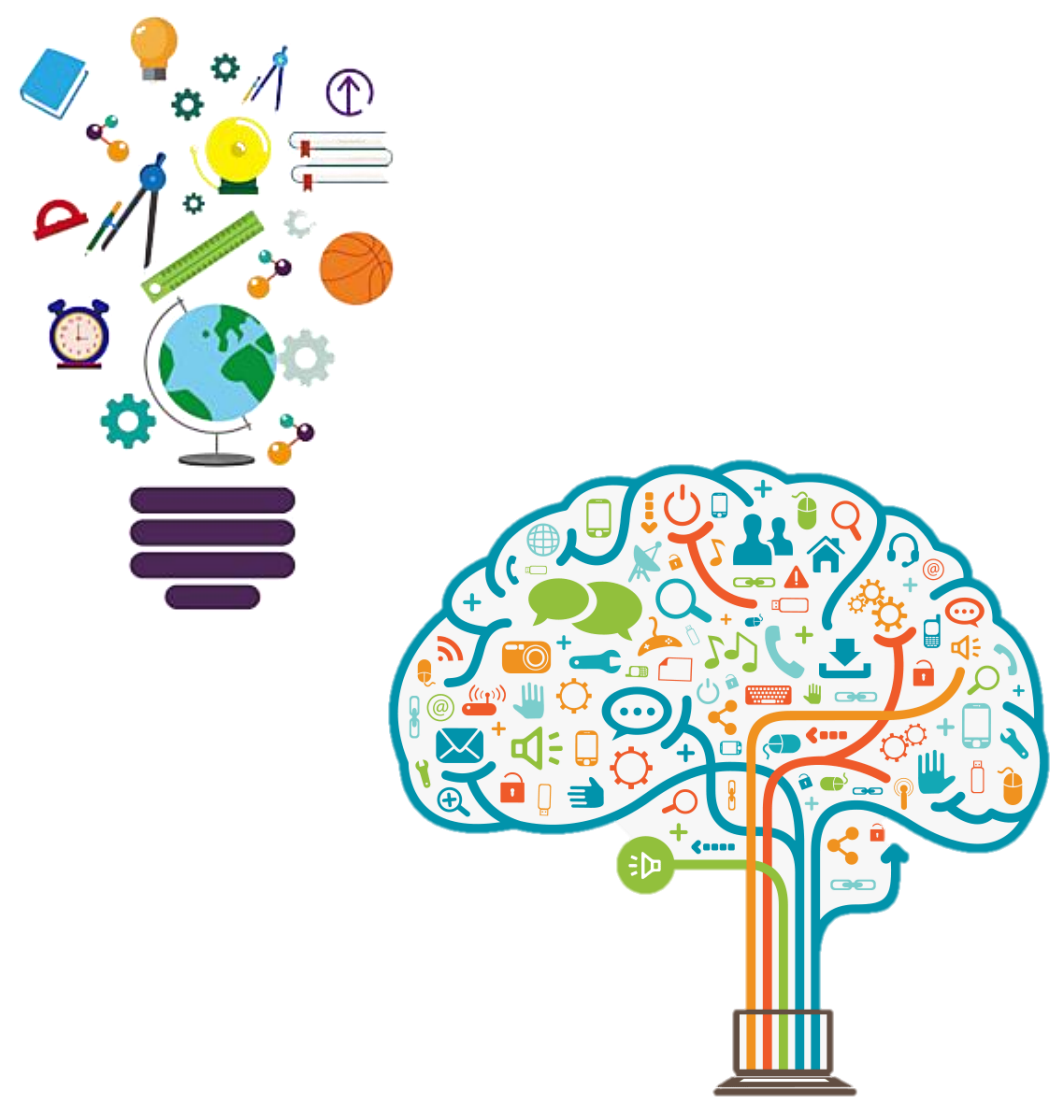




\section{FUNDAMENTOS SOCIOTÉCNICOS}

- Base em experiências anteriores desenvolvidas em projetos de extensão.
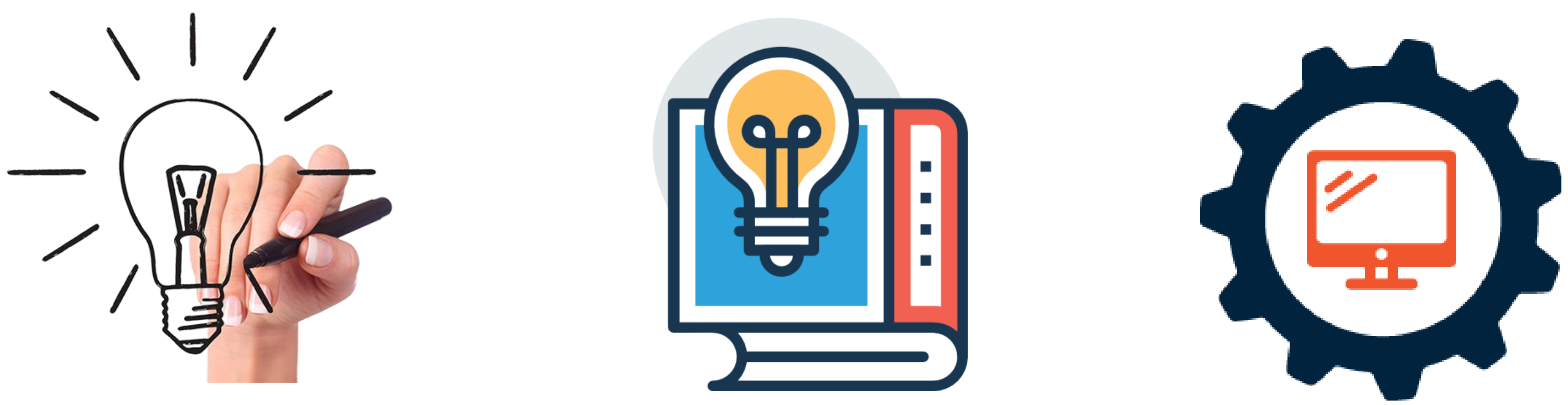


\section{FUNDAMENTOS SOCIOTÉCNICOS}

\section{EMPREENDEDORISMO}

- Capacidade de identificar oportunidades e desenvolver uma solução criando algo positivo para a sociedade;

- Pode ser um negócio, um projeto ou mesmo um movimento que gere mudanças reais e impacto no cotidiano das pessoas;

- Está diretamente associado à inovação.
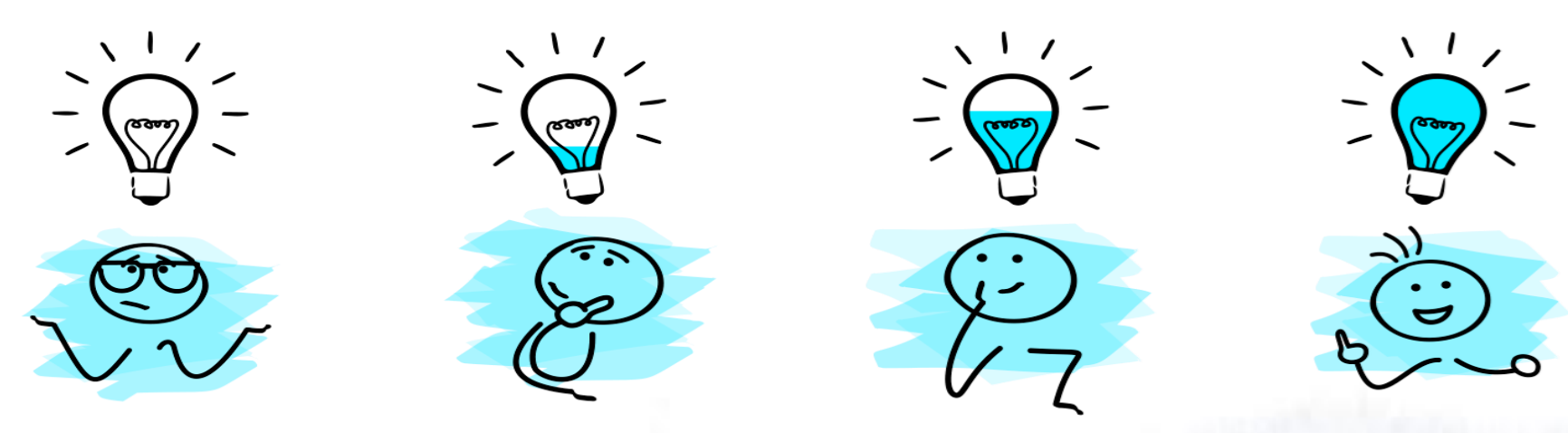


\section{FUNDAMENTOS SOCIOTÉCNICOS}

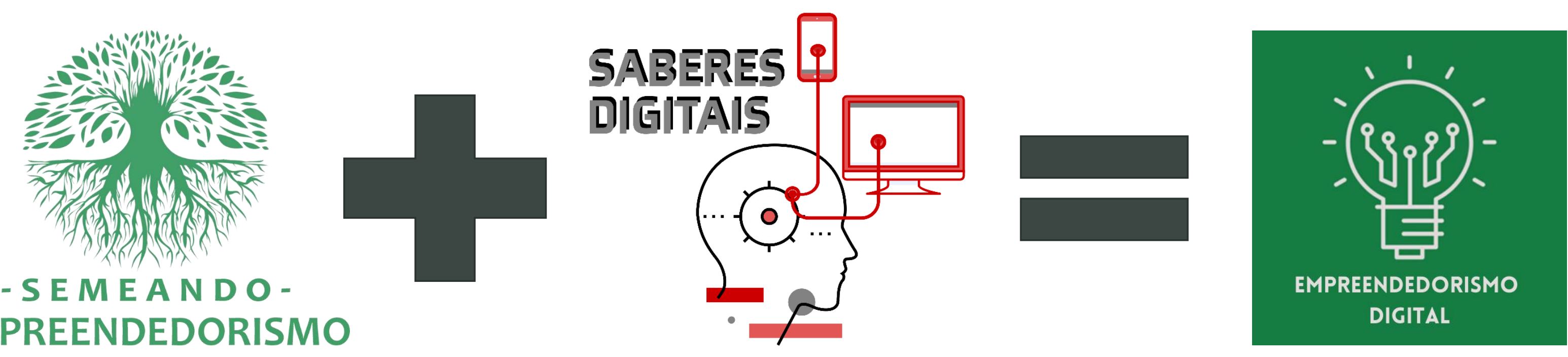
EMPREENDEDORISMO 




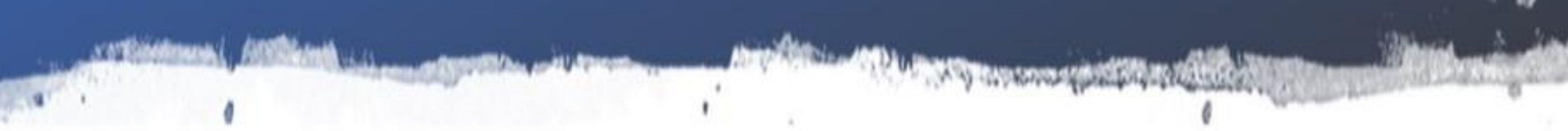

\section{OFICINA EMPREENDEDORISMO DIGITAL}

\section{QUESTIONÁRIO INICIAL}

- Autoavaliação;

- Nivelamento;

- 12 questões.

Nivelação e expectativas Empreendedorismo digital

Este formulário tem o objetivo de compreender e buscar atender aos diversos niveis de conhecimentos dos alunos do curso de empreendedorismo digital. Responda de forma sincera de acordo com o que julgar ser sua realidade ou expectativa.

\section{Nome}

Short answer text

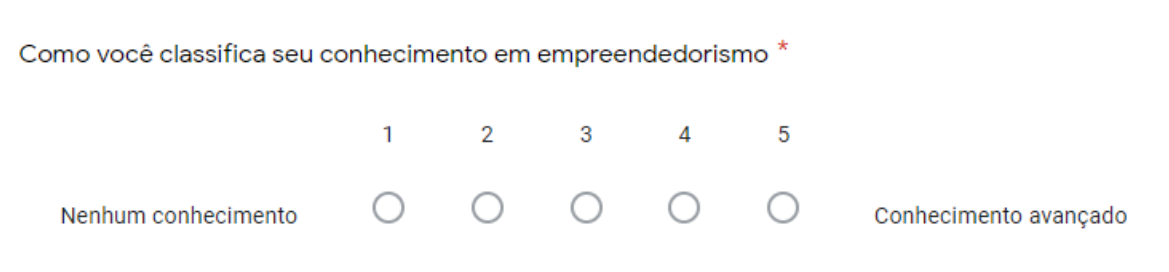

Você já fez algum curso/matéria sobre empreendedorismo? *

sim

Não 




\section{OFICINA EMPREENDEDORISMO DIGITAL}

\section{PROPOSTA DE PROJETO}

- Projeto de um empreendimento;

- Adaptação ao "novo normal";

- Aplicação das habilidades empreendedoras;

- Conhecimentos adquiridos com o empreendimento fictício.

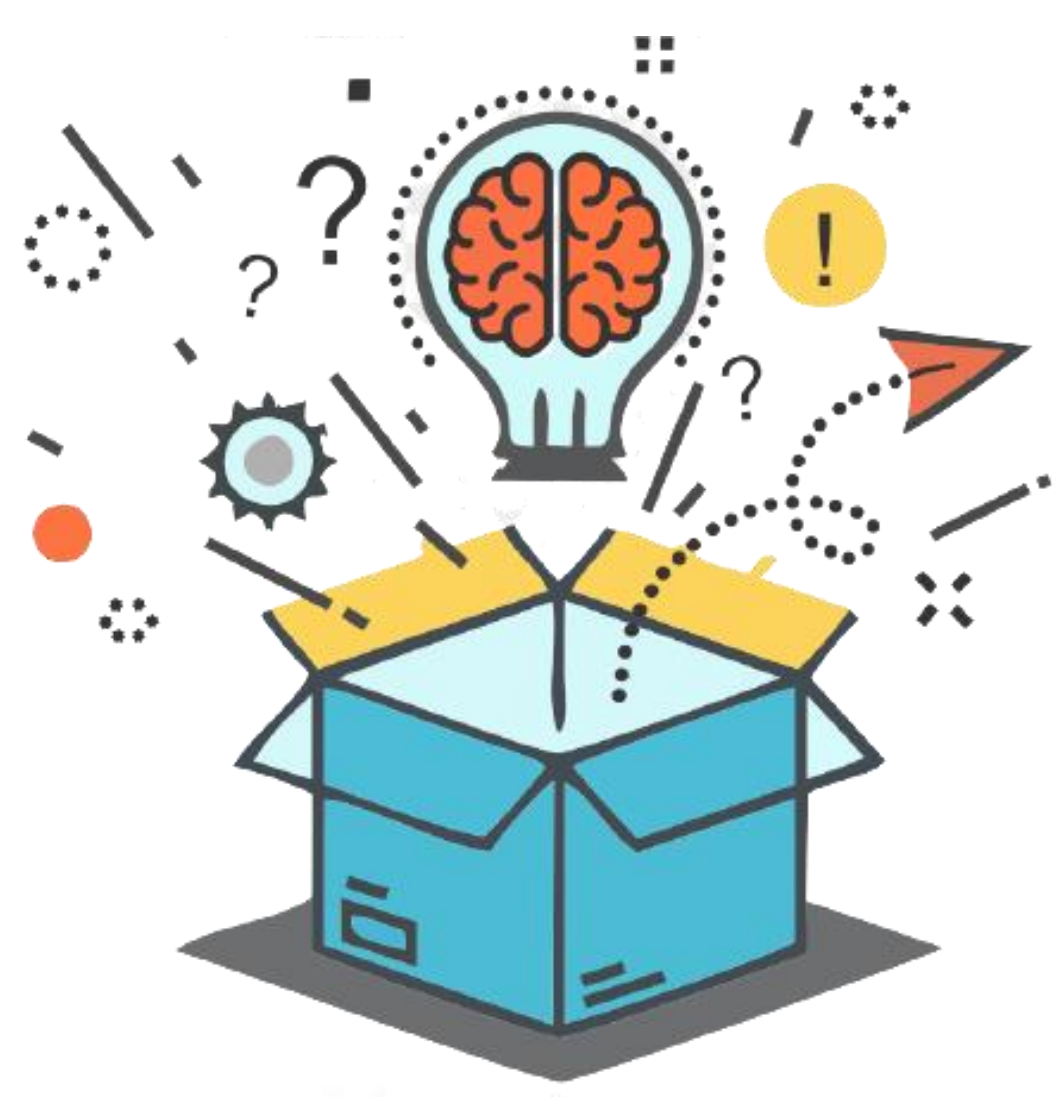




\section{OFICINA EMPREENDEDORISMO DIGITAL}

\section{FERAMENTAS COMPUTACIONAIS}

- Viabilização da execução do projeto;

- Excel, Power Point, programação básica, criação de redes sociais e sites.

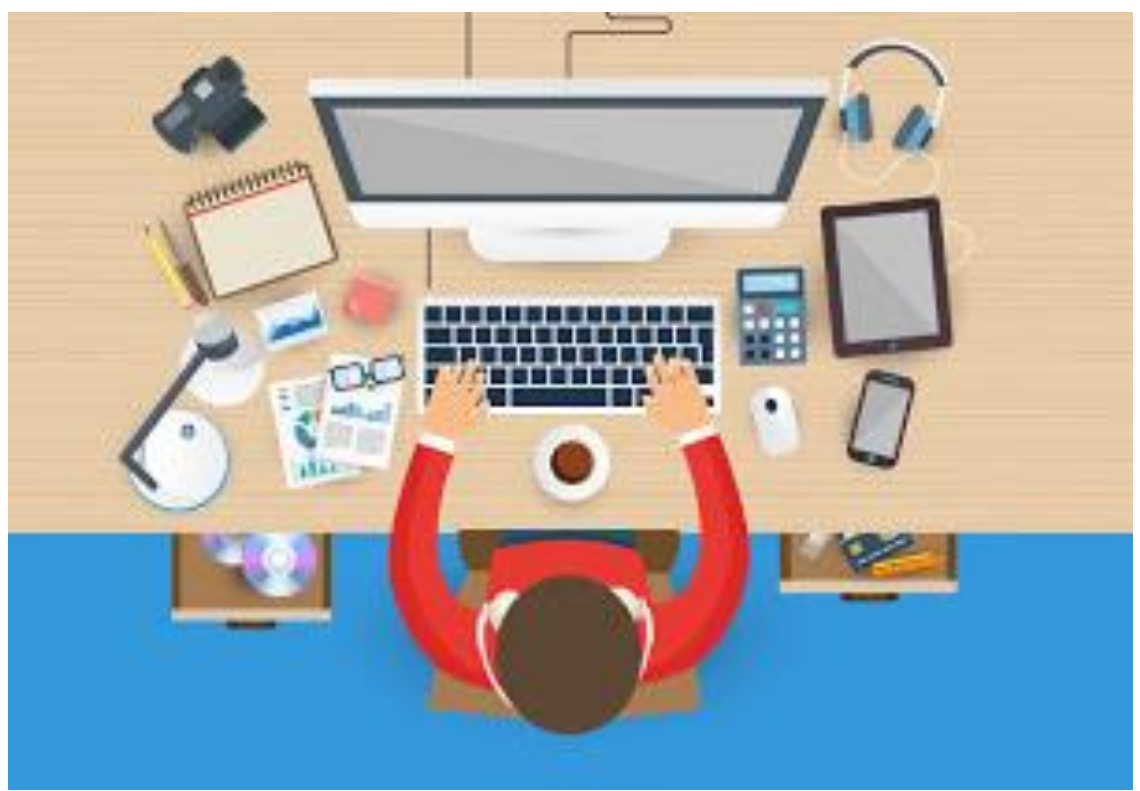




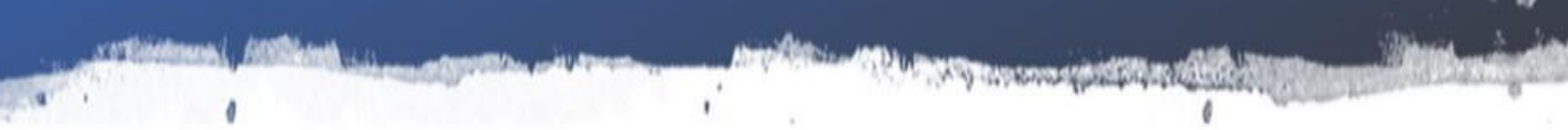

\section{OFICINA EMPREENDEDORISMO DIGITAL}

\section{QUESTIONÁRIO FINAL}

- Validação de expectativas;

- Feedbacks;

- 10 questões.

Avaliação do projeto

Form description

Nome

Short answer text

Após o curso, como você classifica o seu conhecimento em empreendedorismo? *

Nenhum conhecimento $\bigcirc \bigcirc \quad \bigcirc \quad \bigcirc \quad$ conhecimento avançado

O curso, de alguma forma, fomentou seu interesse por empreender?

sim

Não

Um pouco 


\section{RESULTADOS E DISCUSSÃO}

- 48 participantes concluintes com certificado.

\section{PROJETOS DESENVOLVIDOS:}

- Recriando

- Atena consultoria

- Conexão do bem

- Vertentes solidária

- Criança solidária

- Trem di tudo
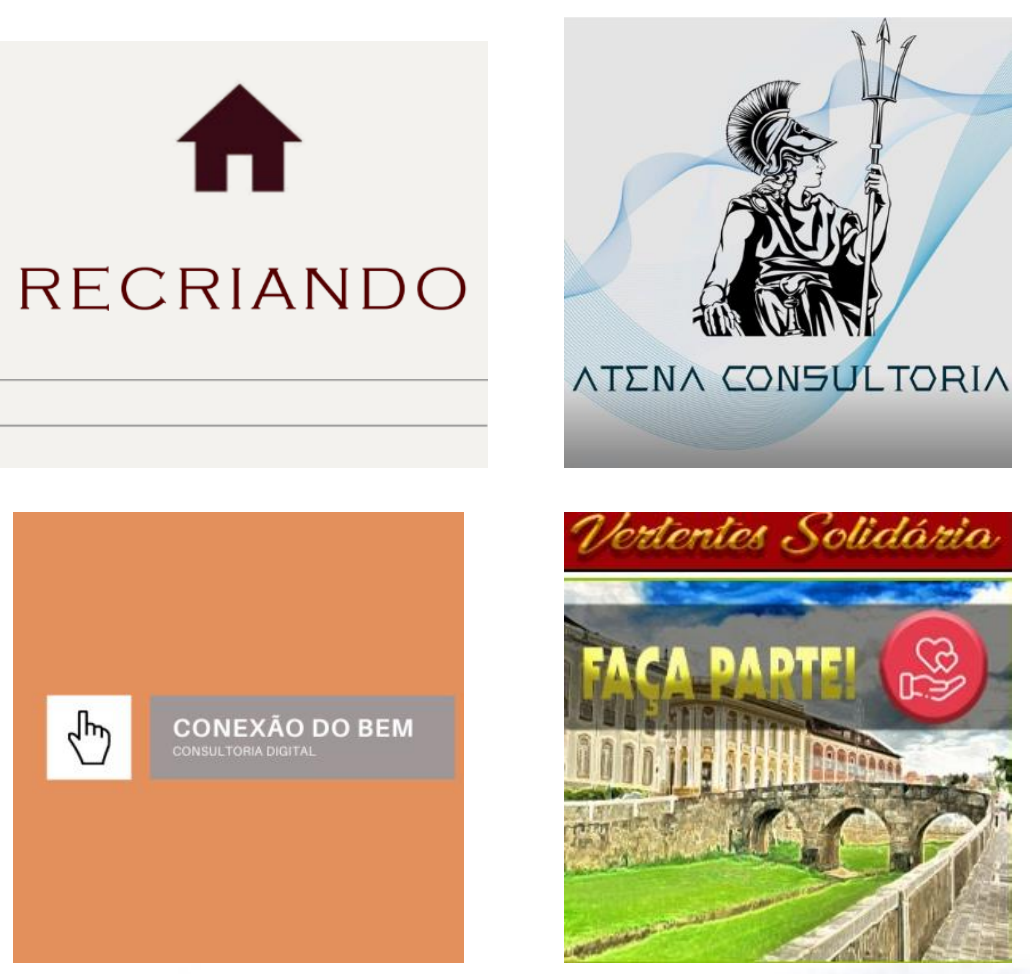

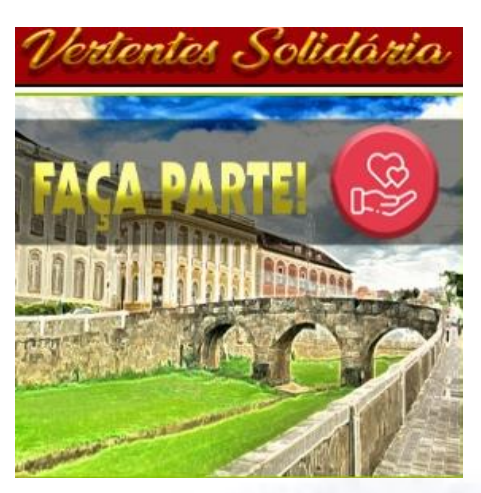

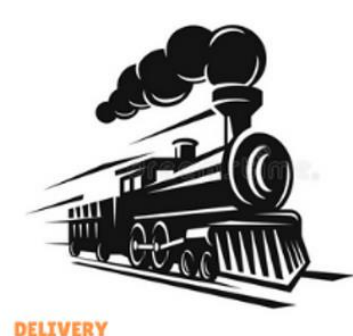

TREM DI TUDO

CRIANÇA SOLIDÁRIA

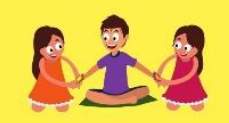




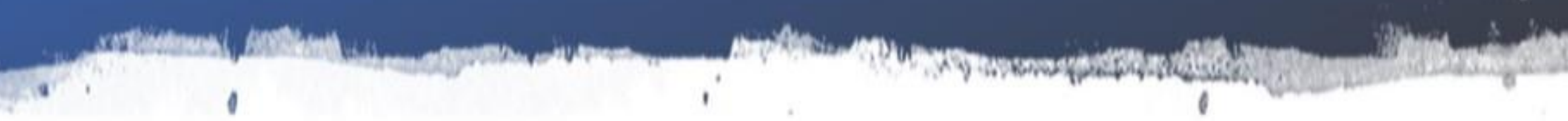

\section{RESULTADOS E DISCUSSÃO}

\section{CASE - ATENA CONSULTORIA}

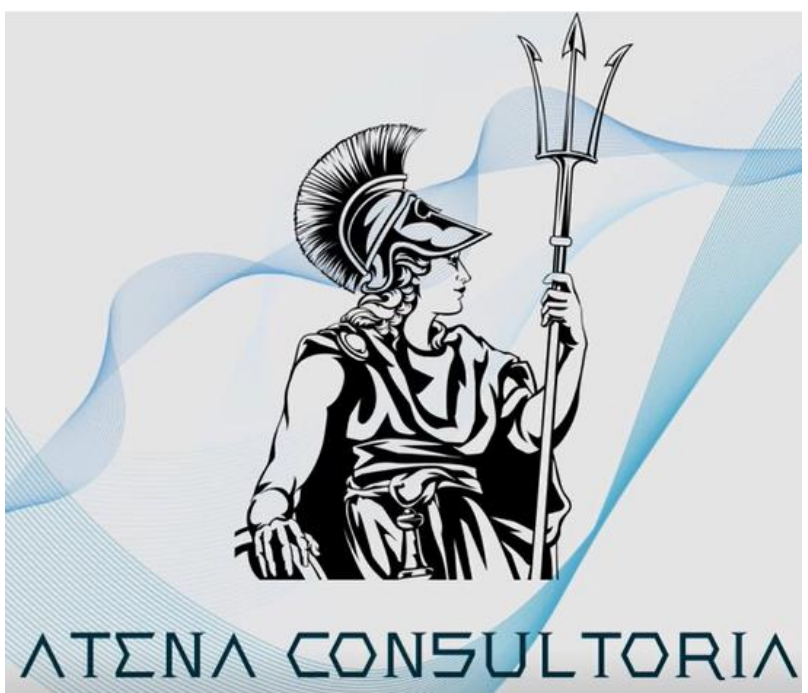

$\wedge T \angle N \wedge$ CONSULTORI^
$20: 05$ is (2) $(1)$

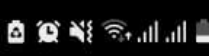

$\leftarrow \quad$ zeninha_festas

○ :

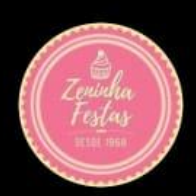

1.144

934

Zeninha Festas

Loja de doces

Bolo, doces, bombons e sobremesas

Feito com amor, cuidado e simplicidade

i Barroso

Pedidos no direct e no WhatsApp 9

Ver tradução
api.whatsapp.com/send?phone $=5532988662118 \&$ text.

api.whatsapp.com/send?phone=5532988662118\&text...

Gerais 36212000

Seguido por larissacorlando, juliadario_e outras 14

pessoas

Seguindo $v$

Mensagem

Contato

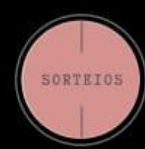





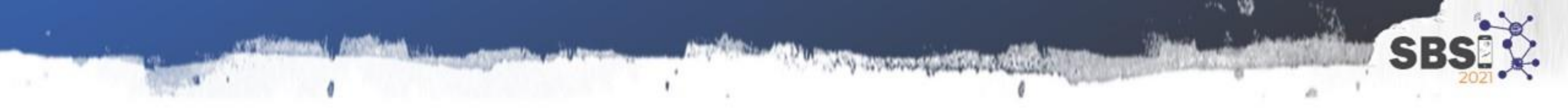

\section{CONCLUSÃO}
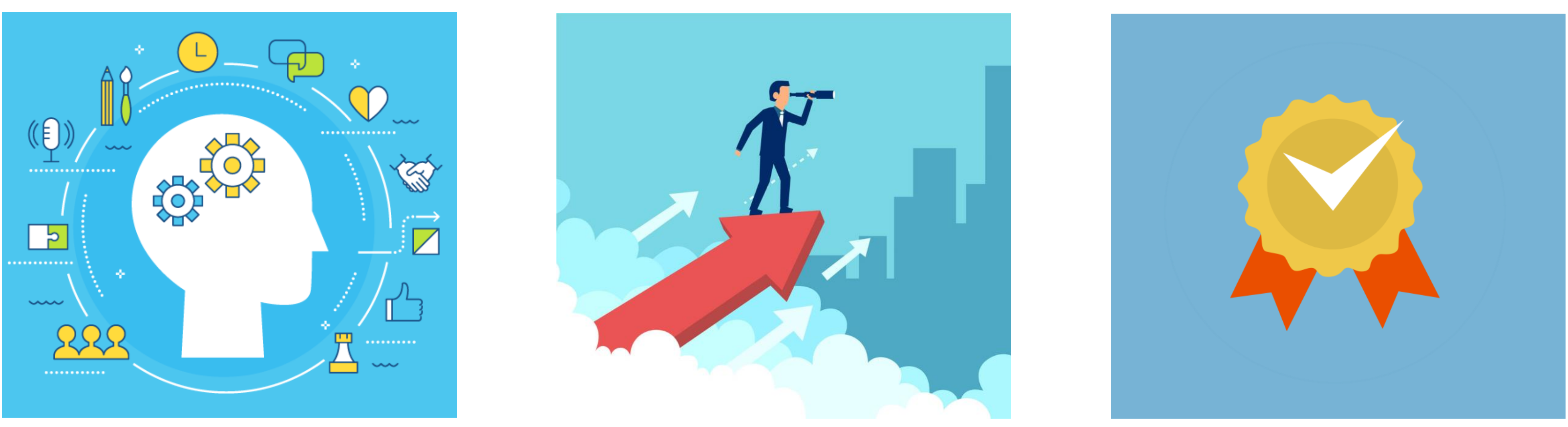


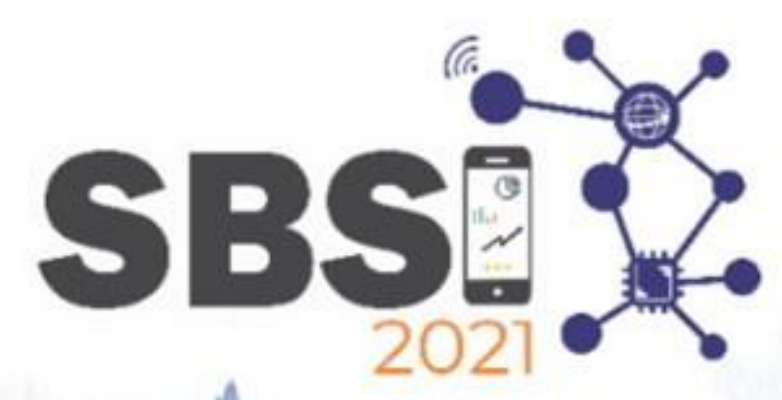

\section{PROMOTING DIGITAL ENTREPRENEURSHIP TO MITIGATE THE IMPACTS CAUSED BY THE COVID- 19 PANDEMIC}

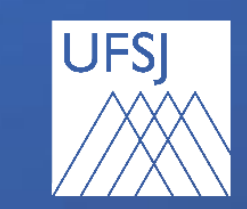
Universidade Federa
Alice Ferreira Cunha (alice_cunha10@hotmail.com) Fábio Corrêa (fabiocontact@gmail.com)

Universidade Federal de São João del-Rei

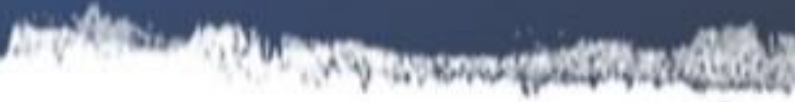

1

\section{UUFU}

Faculdade de Computaçẩo

Organização

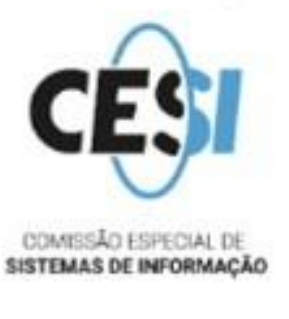

$\widehat{\text { acm }}$ In-Cooperation
Dárlinton Barbosa Feres Carvalho (darlinton@acm.org) Fabrício Molica de Mendonça (fabriciomolica@ufsj.edu.br)

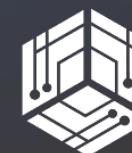

5 I

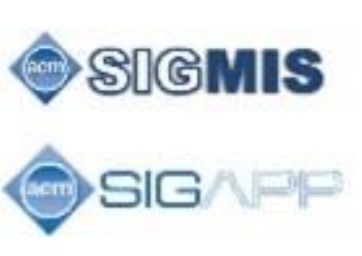

CSIGNVF

Apoio/Cooperação 